\title{
Clinical Experience with Insulin Glargine in Type 1 Diabetes
}

\author{
Satish Garg, M.D., Emily Moser, B.A., Marie-Paule Dain, M.D., ${ }^{2}$ and Anastasia Rodionova, B.A.
}

\begin{abstract}
The Diabetes Control and Complications Trial (DCCT) demonstrated the importance of optimal glycemic control achieved through intensive insulin therapy in reducing the microvascular complications associated with type 1 diabetes. However, the DCCT, which was conducted prior to the availability of insulin analogs, also reported a significant increase in severe hypoglycemia with intensive versus conventional therapy. Insulin analogs were developed to aid patients in achieving better diabetes control by providing insulins with optimized pharmacokinetic and pharmacodynamic characteristics. Insulin glargine was the first long-acting insulin analog with a 24-h duration of action, offering once-daily injection, and has now been in clinical use for over 10 years. The authors performed a systematic search of EMBASE, MEDLINE, and Web of Science (Science Citation Index) to determine the efficacy of insulin glargine in type 1 diabetes in basal-bolus insulin regimens. Randomized controlled trials have demonstrated that glycemic control with insulin glargine is at least comparable to that with neutral protamine Hagedorn (NPH) insulin in adults and in children and adolescents, and with continuous subcutaneous insulin infusion in adults. However, these same trials show a significantly lower risk for hypoglycemia with insulin glargine compared with NPH insulin in adults.
\end{abstract}

\section{Introduction}

T he Diabetes Control and Complications Trial (DCCT) demonstrated the importance of optimal glycemic control achieved through intensive insulin therapy in reducing the microvascular complications associated with type 1 diabetes. ${ }^{1}$ However, the DCCT was conducted before the introduction of pharmacokinetically optimized insulin analogs with properties that offer patients an opportunity for greater control and flexibility in managing their blood glucose (BG) levels. ${ }^{2}$ These properties are found in long-acting basal insulins, which have a longer duration of action, or in rapid-acting prandial insulins, which have a more rapid onset of action with reduced variability in activity. ${ }^{2}$ Insulin glargine was the first basal insulin analog to be approved for patients with diabetes in the year 2000. This analog is modified in such a way that the insulin precipitates in the subcutaneous tissue following injection and is slowly absorbed into the bloodstream. ${ }^{3}$

The properties of the insulin analogs are designed to allow for more accurate replication of the basal and prandial components of insulin replacement with a reduced risk of hypoglycemia compared with equivalent human insulin. ${ }^{2}$ Hypoglycemia is an important limiting factor in achieving glycemic control for patients with type 1 diabetes $^{4}$ and is a significant complication of intensive therapy. Indeed, in the DCCT, the rate of severe hypoglycemia was nearly threefold higher with intensive treatment compared with conventional therapy. ${ }^{5}$ However, the clinical benefits of insulin analogs over regular human insulin (RHI) preparations remain controversial because meta-analyses have identified few advantages. ${ }^{6-9}$ The aim of this review is to provide a descriptive summary of the overall clinical experience with insulin glargine versus neutral protamine Hagedorn (NPH) insulin or continuous subcutaneous insulin infusion (CSII) in adults or children and adolescents with type 1 diabetes as part of a multiple daily injection (MDI) regimen.

\section{Search Strategy}

Electronic databases (EMBASE, MEDLINE, and Web of Science [Science Citation Index]) were searched with a cutoff date of February 15, 2010 inclusive, using the key words "insulin," "glargine," and "type 1 diabetes."

The review was limited to randomized controlled trials in adult and in pediatric populations utilizing once-daily insulin glargine for a minimum of 12 weeks. Studies including pregnant women or other populations are not included in this review. Furthermore, reports that included patients with type 1 and type 2 diabetes were excluded if the authors did not provide separate data for the two diabetes groups.

\section{Data Collection}

The authors recorded the following information from each report (randomized controlled trials), where stated:

\footnotetext{
${ }^{1}$ University of Colorado, Denver, Colorado.
}

${ }^{2}$ sanofi-aventis, Paris, France. 
- Study design

- Study duration

- Number of patients randomized

- Treatments allocated

- Change from baseline in glycosylated hemoglobin (A1C), fasting BG (FBG) or fasting plasma glucose, and 2-h postprandial BG (for rapid-acting insulins)

- Frequency of symptomatic and nocturnal hypoglycemia

\section{Results and Discussion}

The literature search retrieved 26 studies, in which insulin glargine was compared with NPH insulin (13 studies), ultralente (one study), or CSII (five studies) in adults (Table 1). Of these, four studies versus NPH and two studies versus CSII in adults were shorter than 12 weeks and were subsequently excluded. Six studies compared insulin glargine with NPH insulin/lente insulin in children and adolescents (Table 2); one of these studies was excluded because the duration of treatment was $<12$ weeks.

\section{Clinical efficacy and safety with insulin glargine}

Insulin glargine versus NPH insulin. The search identified nine randomized controlled trials that compared insulin glargine with NPH insulin as part of an MDI regimen, ranging in duration from 12 weeks $^{10}$ to 1 year ${ }^{11}$ (Table 1). As summarized in this table, insulin glargine consistently provided significantly ${ }^{10-13}$ or nonsignificantly ${ }^{14}$ greater baselineto-endpoint improvements in FBG than NPH insulin, and this was evident in studies ranging in duration from 12 weeks to 1 year. This difference was apparent both in studies where NPH was administered once daily and in studies where NPH was administered twice daily. The improvement in FBG with insulin glargine over NPH insulin was approximately 1-2 mmol/L. However, two studies reported improvements in FBG $>3 \mathrm{mmol} / \mathrm{L}$ with insulin glargine. ${ }^{15,16}$ The improvements in FBG were associated with small improvements in A1C with both insulins, although A1C increased slightly in one study. ${ }^{14}$ In terms of the magnitude of A1C improvement, four studies showed no difference between the two insulins, ${ }^{12,13,17,18}$ whereas four studies showed significantly greater improvements with insulin glargine compared with NPH insulin, ${ }^{10,11,13,18}$ consistent with improvements in FBG. However, three of these studies used NPH insulin once daily, ${ }^{10,11,16}$ and greater improvements in A1C may have been possible if NPH insulin was used twice daily or if there was an option to add a second daily dose of $\mathrm{NPH}$ insulin in these studies. For example, in the 30-week study by Fulcher et al., ${ }^{16}$ insulin glargine achieved greater improvements in A1C and FBG than once-daily NPH insulin. In contrast, in the study by Bolli et al., ${ }^{17}$ insulin glargine elicited significantly greater improvements in FBG than twicedaily NPH insulin, but the magnitude of A1C improvement was identical in both groups. Thus, it is possible that, although twice-daily NPH insulin does not seem to affect FBG, it may affect other parameters of glucose control, such as postprandial BG, to improve A1C.

Twice-daily insulin glargine has been tested in a crossover study in which 20 patients with type 1 diabetes were given once-daily insulin glargine at dinnertime or twice-daily insulin glargine (half doses at breakfast and dinner). ${ }^{19}$ Over the 4 -week treatment period, the twice-daily regimen resulted in lower BG levels after breakfast, lunch, and before dinner and was also associated with lower mean 24-h BG levels (7.1 vs. $8.8 \mathrm{mmol} / \mathrm{L}$; $P=0.031)$ and less intraday variability in BG levels $(P=0.044)$. The authors concluded that for patients who experience late afternoon increases in BG levels, twice-daily insulin glargine may be a suitable alternative that does not require an increase in insulin dosage, although it is important to note that administering insulin glargine more than once daily is not currently approved by regulators and represents off-label use.

Another outcome that should be considered in the treatment of type 1 diabetes is the prevalence of hypoglycemia. Hypoglycemia is often debilitating and may lead to adverse outcomes. Therefore, in an effort to avoid hypoglycemia, patients may inadequately titrate their insulin, which may ultimately result in suboptimal glycemic control. Reviewing these nine studies, the authors found that insulin glargine was associated with a significantly reduced risk of symptomatic hypoglycemia $10,11,13,17,18$ or no difference in risk ${ }^{12,14-17}$ compared with NPH insulin. These differences were most marked in the studies that administered $\mathrm{NPH}$ insulin once daily. This difference in hypoglycemia between once-daily NPH and insulin glargine is reflected in the recommendations for a dose reduction of $20-30 \%$ when transitioning from once-daily NPH insulin to insulin glargine, while affording the same or better overall efficacy at lower doses.

Insulin glargine versus ultralente. The authors found only one study that compared insulin glargine with ultralente insulin. In this study, once-daily insulin glargine was shown to be associated with greater improvements in A1C and FBG and fewer episodes of hypoglycemia compared with oncedaily ultralente. ${ }^{20}$ However, this was a relatively small study, with only 22 patients, and should be interpreted with caution.

The "dawn phenomenon" and insulin glargine: implications on dose timing. The term "dawn phenomenon" describes hyperglycemia that occurs in the early morning. ${ }^{21}$ Its causes are still not fully understood, but it seems to be related to a combination of the waning of the effects of intermediate-acting insulins, such as NPH insulin, before the next dose and to surges in circulating levels of other hormones, including growth hormone and cortisol, and a reduction in free insulinlike growth factor-1 (IGF-1) levels resulting in greater insulin resistance. ${ }^{22-24}$ It has been suggested that as many as $54 \%$ of patients with type 1 diabetes experience the dawn phenomenon. ${ }^{21}$ Patients with marked hyperglycemia are generally managed with CSII programmed to deliver an increased basal rate at an appropriate time during the night, ${ }^{23}$ although there is some evidence to suggest that long-acting insulin analogs could also provide better control of early morning BG compared with NPH insulin. A nonrandomized study of 48 Japanese patients with type 1 diabetes treated with insulin glargine or NPH insulin as part of an MDI regimen, or CSII at a constant rate, evaluated nocturnal and early morning BG and free IGF-1 levels. ${ }^{25}$ A total of $60 \%$ of patients receiving NPH insulin experienced the dawn phenomenon, whereas BG levels in the glargine and CSII groups were more stable, and few patients experienced the dawn phenomenon. ${ }^{25}$ These differences corresponded with a marked reduction in free IGF-1 with NPH insulin, whereas IGF-1 levels remained relatively stable with CSII and insulin glargine. The authors concluded that the more constant insulin bioavailability with CSII or insulin glargine was effective in managing early-morning BG increases. 


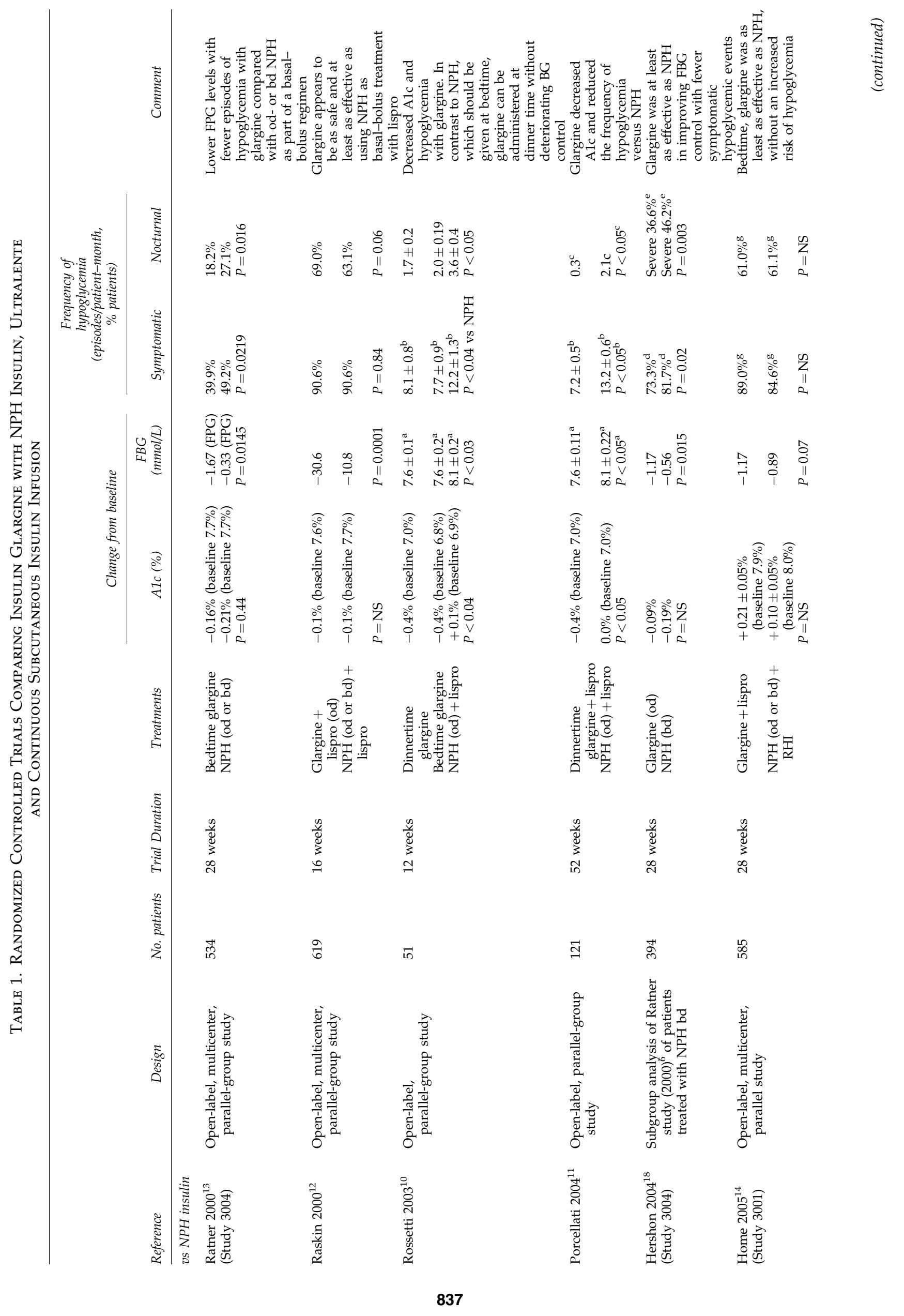




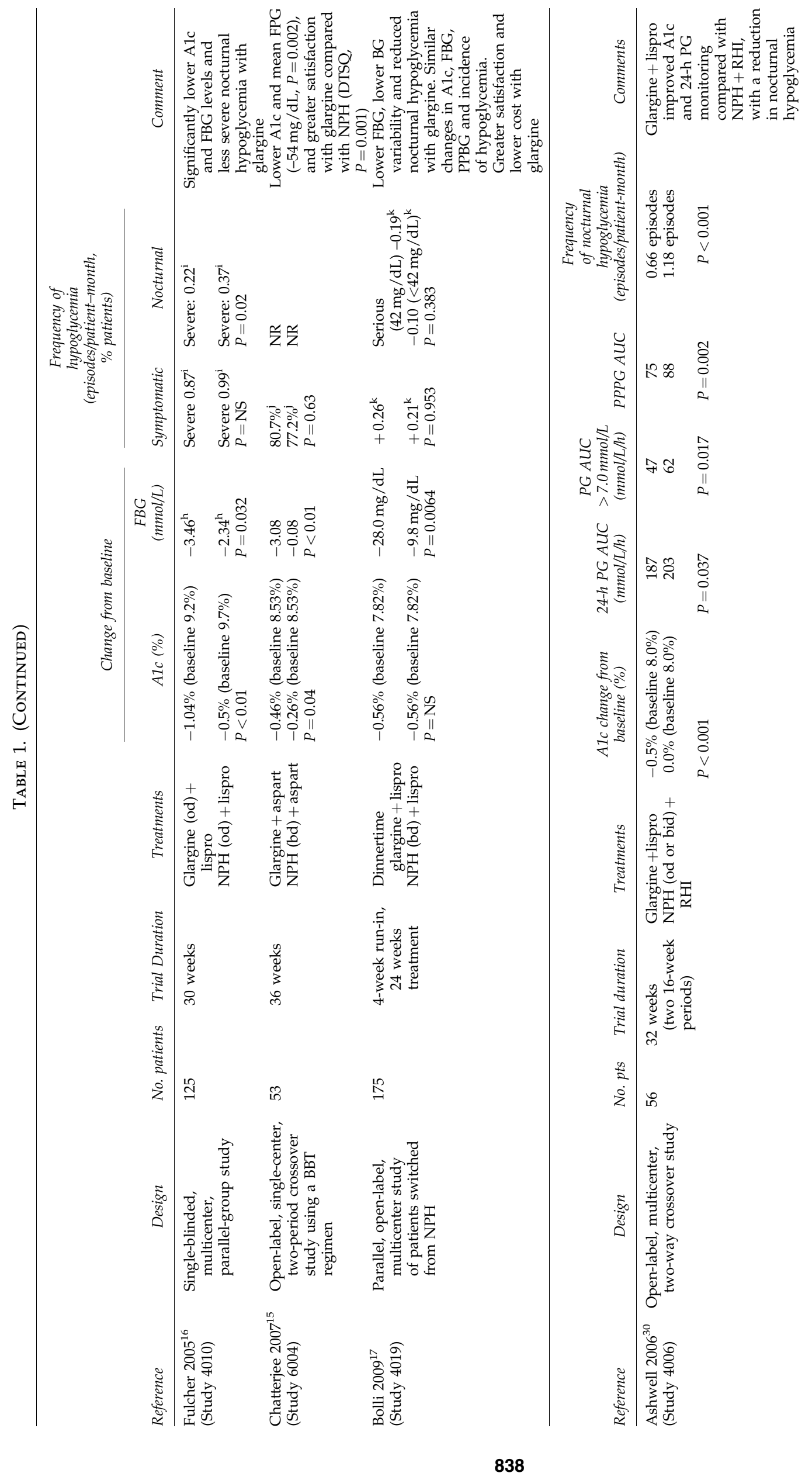




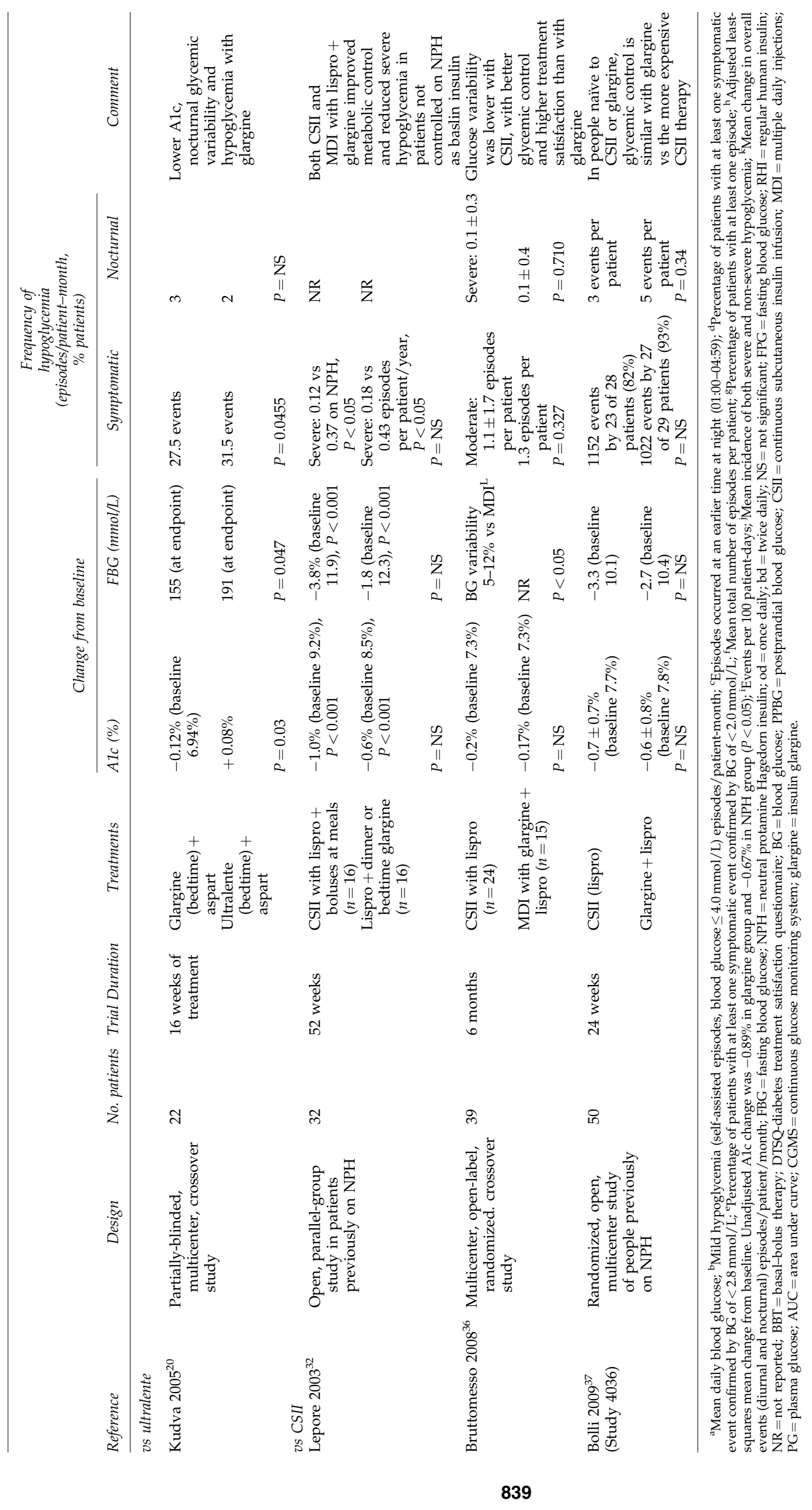




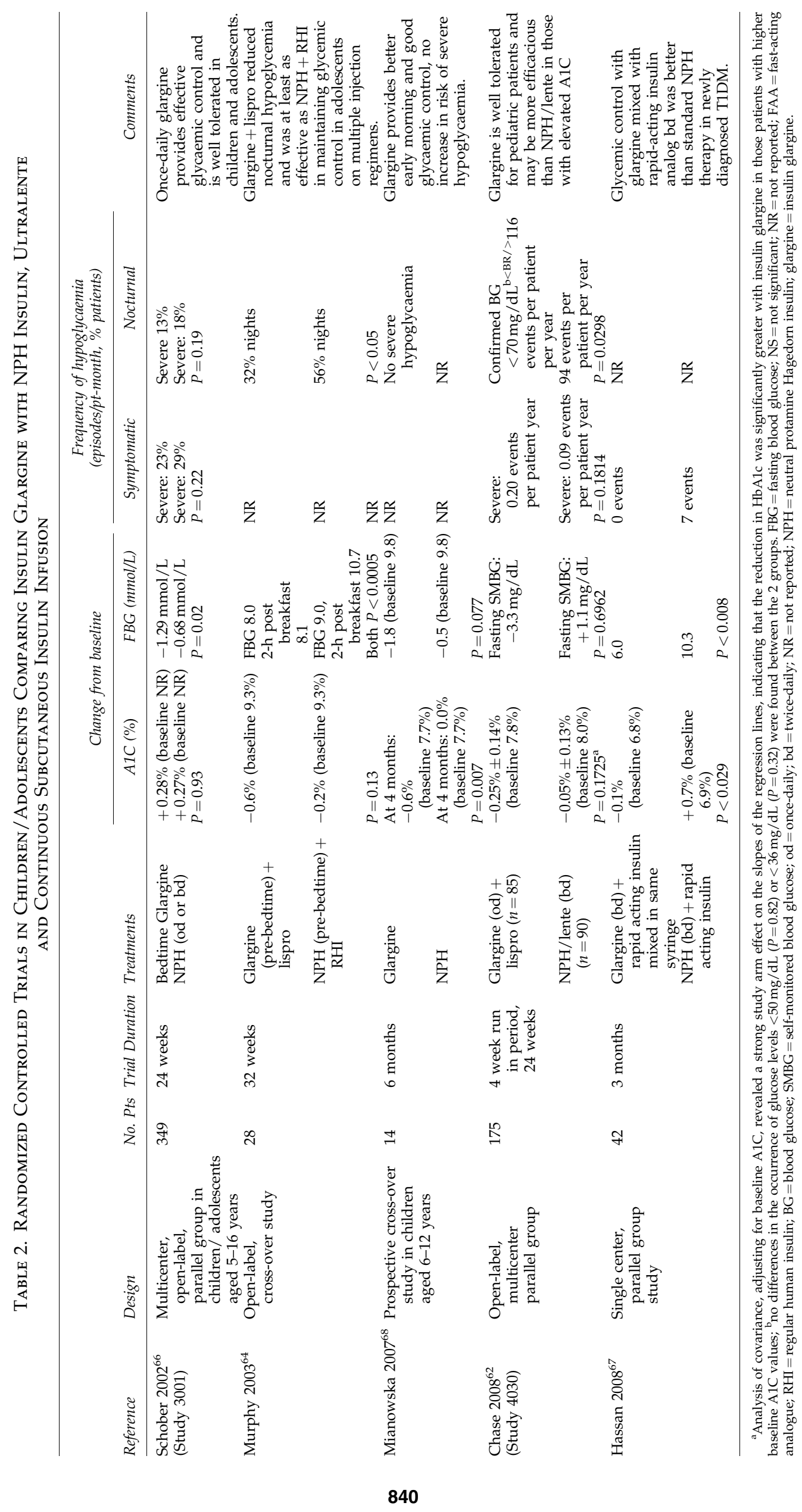


Pharmacokinetic and pharmacodynamic studies have revealed that insulin glargine has a longer duration of action than $\mathrm{NPH}$ insulin. However, the duration of action of insulin glargine may not reach $24 \mathrm{~h}$ in some people, ${ }^{26,27}$ which may be reflected by hyperglycemia shortly before the next administration. In one clinical study that compared the effects of timing of insulin glargine administration (lunchtime, dinnertime, and bedtime) (Table 3), plasma insulin levels tended to wane shortly before the injection, corresponding to a small increase in plasma glucose levels. ${ }^{28}$ This effect was most notable for the dinnertime injection. In a similar study, the FBG levels did not change during the 24-week treatment period when insulin glargine was injected at breakfast, similar to the dawn phenomenon. ${ }^{29}$ The results of these studies suggest that changing the time of insulin glargine injection to lunchtime or bedtime should avoid hyperglycemia before the next insulin glargine injection. This may be explained by the shorter intervals between breakfast and lunch and between dinner and bedtime, compared with that between lunch and dinner, thus providing sufficient insulin cover from the prandial insulin to overcome any waning of insulin glargine..$^{28}$

\section{Combining insulin glargine with a rapid-acting insulin}

As outlined in the previous section, the use of insulin glargine versus other long- and intermediate-acting insulins as part of an MDI regimen in type 1 diabetes has been extensively studied. Almost all of the studies of insulin glargine to date either used insulin glargine in both groups and compared the efficacy of short-acting insulins at mealtimes or used the same short-acting insulin in both groups to compare the efficacy of basal insulin (as described above). The results of studies that compared short-acting insulins alone are beyond the scope of the present review. To the authors' knowledge, only one study in type 1 diabetes has compared insulin glargine plus a rapidacting analog (insulin lispro) versus NPH insulin in combination with RHI. ${ }^{30}$ In that 32-week, two-way crossover study (16 weeks per treatment period), insulin glargine plus insulin lispro achieved a significantly lower A1C compared with NPH insulin plus RHI $(7.5 \%$ vs. $8.0 \% ; P<0.001)$. This was associated with significantly lower 24-h glucose area under the curve (AUC) (187 vs. $203 \mathrm{mmol} / \mathrm{L} / \mathrm{h} ; P=0.037$ ), plasma glucose AUC $>7 \mathrm{mmol} / \mathrm{L}$ ( $47 \mathrm{vs} .62 \mathrm{mmol} / \mathrm{L} / \mathrm{h} ; P=0.017$ ), and postprandial plasma glucose AUC (75 vs. $88 \mathrm{mmol} / \mathrm{L} / \mathrm{h}$ ), although not nighttime plasma glucose AUC or plasma glucose AUC $<3.5 \mathrm{mmol} / \mathrm{L}$. The total rate of symptomatic hypoglycemia was comparable (1,277 vs. 1,327 episodes), but the rate of symptomatic nocturnal hypoglycemia was significantly lower with insulin glargine plus insulin lispro $(0.66 \pm 0.02$ vs. $1.18 \pm 0.02$ episodes/month; $P<0.001)$. Most episodes of nocturnal hypoglycemia occurred at 06:00-0:700 $\mathrm{h}$ with insulin glargine plus insulin lispro versus 00:00-04:00 h with NPH insulin plus RHI.

\section{Insulin glargine-based MDI therapy versus CSII}

The authors found three clinical studies that compared insulin glargine-based MDI with CSII, all of which used insulin lispro in the CSII group. ${ }^{31-37}$ As summarized in Table 1, these studies show comparable or marginally greater improvements in glycemic control and lower rates of hypoglycemia with CSII versus MDI therapy with insulin glargine, indicating that CSII may be more effective than MDI therapy with insulin glargine. However, most of these studies were relatively small in size, limiting the ability to detect differences in either regimen. In addition, CSII allows the delivery of multiple basal rates, which might help mitigate the dawn phenomenon. Larger, better-designed studies with appropriate powering may help to better understand the relative impact of CSII and insulin glargine-based MDI on glycemic control and hypoglycemia in patients with type 1 diabetes.

\section{Implications of insulin analogs for the treatment of type 1 diabetes in adults}

As described above, insulin analogs provide improved pharmacokinetic and pharmacodynamic characteristics relative to the respective human insulin. Since their introduction, it has been proposed that these properties confer advantages for the treatment of diabetes, particularly in terms of reduced risk of hypoglycemia, which has been demonstrated in meta regression analyses for insulin glargine ${ }^{6}$ and insulin detemir. ${ }^{9}$ The reduced risk of hypoglycemia with insulin glargine relative to NPH insulin may enable more patients to achieve treatment targets, through more aggressive titration of the insulin dose. Studies show that basal insulin analogs provide potentially important improvements in glycemic control that should reduce the risk of diabetes-related complications with long-term intensive therapy. The flexibility of insulin glargine dosing in relation to timing of administration has also been demonstrated (and approved by the Food and Drug Administration) - in particular, the opportunity for administration at breakfast, dinnertime, or bedtime, providing the timing of daily injection is constant. $28,29,38$

As described previously in this review, insulin analogs provide clinically important improvements in glycemic control within a tightly controlled clinical trial setting; but how is this evidence reflected in everyday clinical practice? Observational studies are generally regarded as the best approach to assess the actual health outcomes of patients in routine care. ${ }^{39,40}$ This is because the level of care patients receive in clinical trials is often of a different standard and not representative of that seen in daily clinical practice, particularly with respect to patient populations and medication adherence. ${ }^{41,42}$ In addition, clinical trials may include a limited scope of titration with other glucose-lowering drugs (or other concomitant treatments), a relatively short observational period, and potential for population bias, which may prevent extrapolation of findings to everyday practice. ${ }^{43,44}$

Therefore, what is the evidence in less rigorously controlled settings, where patients may receive less support from their clinician? There is ample evidence from everyday clinical practice to demonstrate the efficacy of insulin analogs. ${ }^{45-61}$ Switching to insulin analog-based MDI regimens was associated with marked improvements in glycemic control. For example, in an observational study of 1,942 patients who were switched from NPH insulin to insulin glargine, mean A1C declined by $0.8 \%$ over 6 weeks of treatment, from $8.0 \%$ at baseline. ${ }^{56}$ In a second study of longer duration, 1,447 patients who were switched from various insulin regimens to basalbolus therapy with insulin glargine and insulin glulisine experienced a significant mean reduction in A1C of $1 \%$ over 6 months from a baseline of $8.0 \%{ }^{54}$ These findings support the evidence gained in randomized controlled trials. Nevertheless, one must interpret such studies with care, because of the lack of a comparator group, and the potential for bias through patient 


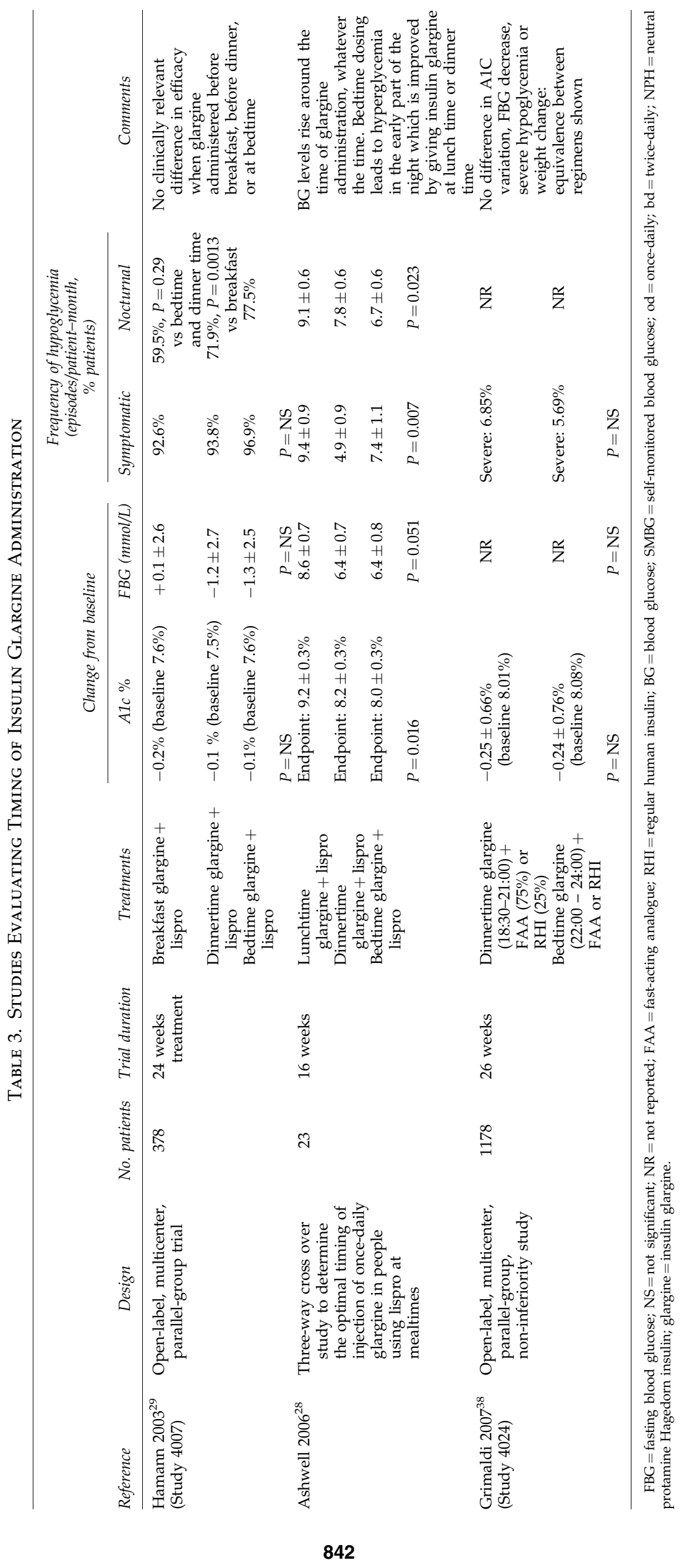


selection, and limited data collection-hypoglycemia, for example, is often under-reported in such studies.

\section{Insulin analogs in children and adolescents}

Several studies have been performed to evaluate the efficacy of insulin glargine in children and adolescents. These studies are important because type 1 diabetes is usually diagnosed at a young age, and pediatric treatment represents an important aspect of managing the condition. The literature search identified six studies (seven publications) ${ }^{62-68}$ in children, ranging in duration from 9 weeks to 32 weeks (Table 2). However, the small sample size ( $<50$ patients) in most of these studies limits their validity. The other two studies enrolled 349 and 175 patients and compared insulin glargine with either NPH insulin (once or twice daily) ${ }^{65,66}$ or NPH insulin/lente insulin. ${ }^{62}$ In the study by Schober et al. ${ }^{65,66}$ with children and adolescents 5-16 years of age, insulin glargine was associated with significantly greater improvements in FBG, although this did not translate into improvements in A1C. In the study by Chase et al. ${ }^{62}$ in adolescents and teenagers 9-17 years of age, there were no differences in the magnitude of improvement in A1C. However, after adjusting for baseline $\mathrm{A} 1 \mathrm{C}$, the change in $\mathrm{A} 1 \mathrm{C}$ was significantly greater with insulin glargine than with NPH insulin/lente insulin. In terms of hypoglycemia, the study by Schober et al. ${ }^{65,66}$ revealed no difference in the rate of hypoglycemia, whereas the study by Chase et al. ${ }^{62}$ revealed higher rates of confirmed hypoglycemia with BG $<70 \mathrm{mg} / \mathrm{dL}$ (116 vs. 94 events/ patient-year, $P=0.0298$ ).

\section{Treatment flexibility and treatment satisfaction}

Insulin analogs provide several functional advantages that may increase treatment satisfaction for patients with diabetes. Clinical studies show that insulin glargine provides flexible basal insulin control with the option of once-daily administration at any time of day. ${ }^{28,29,38}$ Insulin glargine, compared with NPH insulin, is also associated with lower rates of hypoglycemia, a side effect that patients find particularly distressing. Rapid-acting insulin analogs provide flexibility, with the possibility of injecting immediately after a meal constituting an important advantage because of the potential to administer a dose of insulin appropriate for the meal size/content. It has been reported that insulin analogs are associated with greater treatment satisfaction relative to NPH insulin in patients with type 1 diabetes. ${ }^{69,70}$ Ashwell et al. ${ }^{69}$ compared quality of life (QoL) and treatment satisfaction with MDI regimens based on insulin glargine plus insulin lispro versus NPH insulin plus RHI. Over 32 weeks of treatment, insulin glargine plus insulin lispro significantly improved treatment satisfaction and patient QoL compared with the NPH plus RHI regimen.

However, data on the impact of insulin therapy on patient satisfaction and QoL remain limited in type 1 diabetes. These outcomes should be evaluated in more detail in future clinical trials because there is some evidence that such factors not only influence patients' perceptions of their condition, but also their adherence to treatment. Indeed, patients reporting poor QoL or poor treatment satisfaction may be less likely to adhere to their treatment. ${ }^{71-73}$ Furthermore, as reported by Samann et al. ${ }^{74}$ flexible, intensive insulin therapy with dietary freedom can achieve significant improvements in glycemic control without increasing the risk of severe hypoglycemia. Such treatment flexibility with insulin analogs ${ }^{75}$ may be especially important to reduce the incidence of hypoglycemia in children and adolescents, particularly considering their unpredictable lifestyles.

\section{Limitations}

The authors performed a comprehensive literature search to retrieve reports describing the use of insulin glargine versus $\mathrm{NPH}$ insulin for the treatment of type 1 diabetes. However, some limitations should be discussed. First, the search was limited to EMBASE, MEDLINE, and Web of Science. However, it is possible that some studies published in journals not indexed in any of these databases were missed, particularly non-English journal articles. Second, the present analysis was limited to randomized controlled trials; this is recommended to avoid possible bias associated with non-randomized cohort studies or retrospective reviews of medical databases. However, the authors identified a large number of such studies involving several thousand patients that may greatly influence the overall interpretation, as such studies may better reflect everyday clinical practice and patient expectations for treatment. Third, although QoL is an important factor in the holistic effects of insulin therapy, few studies to date have assessed QoL or reported data if the studies did assess QoL. Moreover, the reports that did include QoL did not routinely use the same questionnaire(s). Therefore, a meaningful assessment of QoL could not be provided by this review.

\section{Conclusions}

This review provides a summary of the considerable evidence obtained for insulin glargine in type 1 diabetes since its approval, representing more than 10 years of clinical experience. The data show that insulin glargine provides consistent insulin delivery lasting up to $24 \mathrm{~h}$, which permits once-daily dosing. Insulin glargine provides glycemic control that is at least comparable with NPH insulin, particularly once-daily NPH insulin, in adults, adolescents, and children. However, insulin glargine is also generally associated with a significantly lower risk of hypoglycemia compared with NPH insulin in adults. This latter observation represents an important clinical difference given the fact that hypoglycemia is established as one of the key limiting factors in the achievement of glycemic control. There is also some evidence to suggest that, as part of an MDI regimen, combining insulin glargine with a rapid-acting insulin analog provides benefits over intermediate- and short-acting human insulin-based regimens. The literature search revealed no evidence to demonstrate the superiority of insulin glargine-based MDI or CSII. However, the paucity of well-designed, large-scale trials means more studies are needed in this area.

In conclusion, basal-bolus insulin regimens or CSII should be considered a treatment of choice for type 1 diabetes. The use of long- and short-acting insulin analogs within these regimens offers significant clinical advantages over intermediate- and short-acting human insulins that may enable more patients to reach glycemic targets and reduce the considerable burden of complications associated with poor control in patients with type 1 diabetes.

\section{Acknowledgments}

The contents of this article and opinions expressed within are those of the authors, and it was the decision of the authors to submit the manuscript for publication. M.-P.D. co-ordinated 
the literature search and the organization of the data. All authors critically reviewed the manuscript, including editing of each draft, and approved the final version for submission. Editorial support was provided by Huw Jones, PhD, Medicus International and funded by sanofi-aventis.

\section{Author Disclosure Statement}

S.G. has received research grants from NovoNordisk, sanofi-aventis, and Eli Lilly and Co. M.-P.D. is an employee of sanofi-aventis. E.M. and A.R. have no conflicts of interest to disclose.

\section{References}

1. The effect of intensive treatment of diabetes on the development and progression of long-term complications in insulin-dependent diabetes mellitus. The Diabetes Control and Complications Trial Research Group. N Engl J Med 1993;329:977-986.

2. Hirsch IB: Insulin analogues. N Engl J Med 2005;352: 174-183.

3. Coppolino R, Coppolino S, Villari V: Study of the aggregation of insulin glargine by light scattering. J Pharm Sci 2006;95:1029-1034.

4. ter Braak EW, Appelman AM, van de Laak M, Stolk RP, van Haeften TW, Erkelens DW: Clinical characteristics of type 1 diabetic patients with and without severe hypoglycemia. Diabetes Care 2000;23:1467-1471.

5. Effect of intensive therapy on the microvascular complications of type 1 diabetes mellitus. JAMA 2002;287:25632569.

6. Mullins $\mathrm{P}$, Sharplin $\mathrm{P}, \mathrm{Yki}$-Jarvinen $\mathrm{H}$, Riddle MC, Haring HU: Negative binomial meta-regression analysis of combined glycosylated hemoglobin and hypoglycemia outcomes across eleven Phase III and IV studies of insulin glargine compared with neutral protamine Hagedorn insulin in type 1 and type 2 diabetes mellitus. Clin Ther 2007;29:1607-1619.

7. Singh SR, Ahmad F, Lal A, Yu C, Bai Z, Bennett H: Efficacy and safety of insulin analogues for the management of diabetes mellitus: a meta-analysis. CMAJ 2009;180:385-397.

8. Monami M, Marchionni N, Mannucci E: Long-acting insulin analogues vs. NPH human insulin in type 1 diabetes. A meta-analysis. Diabetes Obes Metab 2009;11:372-378.

9. Hermansen K, Heller S, Andersen M, Russell-Jones D: Insulin detemir reduces hypoglycemic risk at comparable $\mathrm{HbA1c}$ values compared to NPH insulin in patients with Type 1 diabetes [abstract 2059-PO]. Diabetes 2009;58(Suppl 1):A529-A530.

10. Rossetti P, Pampanelli S, Fanelli C, Porcellati F, Costa E, Torlone E, Scionti L, Bolli GB: Intensive replacement of basal insulin in patients with type 1 diabetes given rapid-acting insulin analog at mealtime: a 3-month comparison between administration of NPH insulin four times daily and glargine insulin at dinner or bedtime. Diabetes Care 2003;26: 1490-1496.

11. Porcellati F, Rossetti P, Pampanelli S, Fanelli CG, Torlone E, Scionti L, Perriello G, Bolli GB: Better long-term glycaemic control with the basal insulin glargine as compared with $\mathrm{NPH}$ in patients with Type 1 diabetes mellitus given mealtime lispro insulin. Diabet Med 2004;21:1213-1220.

12. Raskin P, Klaff L, Bergenstal R, Halle JP, Donley D, Mecca T: A 16-week comparison of the novel insulin analog insulin glargine (HOE 901) and NPH human insulin used with insulin lispro in patients with type 1 diabetes. Diabetes Care 2000;23:1666-1671.

13. Ratner RE, Hirsch IB, Neifing JL, Garg SK, Mecca TE, Wilson CA: Less hypoglycemia with insulin glargine in intensive insulin therapy for type 1 diabetes. U.S. Study Group of Insulin Glargine in Type 1 Diabetes. Diabetes Care 2000;23:639-643.

14. Home PD, Rosskamp R, Forjanic-Klapproth J, Dressler A: A randomized multicentre trial of insulin glargine compared with NPH insulin in people with type 1 diabetes. Diabetes Metab Res Rev 2005;21:545-553.

15. Chatterjee S, Jarvis-Kay J, Rengarajan T, Lawrence IG, McNally PG, Davies MJ: Glargine versus NPH insulin: efficacy in comparison with insulin aspart in a basal bolus regimen in type 1 diabetes - the glargine and aspart study (GLASS) a randomised cross-over study. Diabetes Res Clin Pract 2007;77:215-222.

16. Fulcher GR, Gilbert RE, Yue DK: Glargine is superior to neutral protamine Hagedorn for improving glycated haemoglobin and fasting blood glucose levels during intensive insulin therapy. Intern Med J 2005;35:536-542.

17. Bolli GB, Songini M, Trovati M, Del Prato S, Ghirlanda G, Cordera R, Trevisan R, Riccardi G, Noacco C: Lower fasting blood glucose, glucose variability and nocturnal hypoglycaemia with glargine vs NPH basal insulin in subjects with Type 1 diabetes. Nutr Metab Cardiovasc Dis 2009;19:571-579.

18. Hershon KS, Blevins TC, Mayo CA, Rosskamp R: Once-daily insulin glargine compared with twice-daily NPH insulin in patients with type 1 diabetes. Endocr Pract 2004;10:10-17.

19. Ashwell SG, Gebbie J, Home PD: Twice-daily compared with once-daily insulin glargine in people with Type 1 diabetes using meal-time insulin aspart. Diabet Med 2006;23:879-886.

20. Kudva YC, Basu A, Jenkins GD, Pons GM, Quandt LL, Gebel JA, Vogelsang DA, Smith SA, Rizza RA, Isley WL: Randomized controlled clinical trial of glargine versus ultralente insulin in the treatment of type 1 diabetes. Diabetes Care 2005;28:10-14.

21. Carroll MF, Schade DS: The dawn phenomenon revisited: implications for diabetes therapy. Endocr Pract 2005;11: 55-64.

22. Perriello G, De Feo P, Torlone E, Fanelli C, Santeusanio F, Brunetti P, Bolli GB: Nocturnal spikes of growth hormone secretion cause the dawn phenomenon in type 1 (insulindependent) diabetes mellitus by decreasing hepatic (and extrahepatic) sensitivity to insulin in the absence of insulin waning. Diabetologia 1990;33:52-59.

23. Koivisto VA, Yki-Järvinen $\mathrm{H}$, Helve E, Karonen SL, Pelkonen R: Pathogenesis and prevention of the dawn phenomenon in diabetic patients treated with CSII. Diabetes 1986;35:78-82.

24. Kobayashi K, Amemiya S, Sawanobori E, Higashida K, Ishihara T, Kobayashi K, Kato K, Nakazawa S: Role of IGF binding protein-1 in the dawn phenomenon and glycemic control in children and adolescents with IDDM. Diabetes Care 1997;20:1442-1447.

25. Yagasaki H, Kobayashi K, Saitou T, Nagamine K, Mitsui $Y$, Mochizuki M, Kobayashi K, Cho H, Ohyama K, Amemiya S, Nakazawa S: Nocturnal blood glucose and IGFBP-1 changes in type 1 diabetes: differences in the dawn phenomenon between insulin regimens. Exp Clin Endocrinol Diabetes 2010;118:195-199.

26. Heise T, Nosek L, Ronn BB, Endahl L, Heinemann L, Kapitza C, Draeger E: Lower within-subject variability of 
insulin detemir in comparison to NPH insulin and insulin glargine in people with type 1 diabetes. Diabetes 2004;53: 1614-1620.

27. Lepore M, Pampanelli S, Fanelli C, Porcellati F, Bartocci L, Di Vincenzo A, Cordoni C, Costa E, Brunetti P, Bolli GB: Pharmacokinetics and pharmacodynamics of subcutaneous injection of long-acting human insulin analog glargine, NPH insulin, and ultralente human insulin and continuous subcutaneous infusion of insulin lispro. Diabetes 2000;49: 2142-2148.

28. Ashwell SG, Gebbie J, Home PD: Optimal timing of injection of once-daily insulin glargine in people with Type 1 diabetes using insulin lispro at meal-times. Diabet Med 2006;23: $46-52$.

29. Hamann A, Matthaei S, Rosak C, Silvestre L: A randomized clinical trial comparing breakfast, dinner, or bedtime administration of insulin glargine in patients with type 1 diabetes. Diabetes Care 2003;26:1738-1744.

30. Ashwell SG, Amiel SA, Bilous RW, Dashora U, Heller SR, Hepburn DA, Shutler SD, Stephens JW, Home PD: Improved glycaemic control with insulin glargine plus insulin lispro: a multicentre, randomized, cross-over trial in people with Type 1 diabetes. Diabet Med 2006;23:285-292.

31. Bragd J, Adamson U, Lins PE, Von Dobeln A, Oskarsson P: Basal insulin substitution with glargine or CSII in adult type I diabetes patients-a randomized controlled trial [abstract 229-OR]. Diabetes 2009;58:A60.

32. Lepore G, Dodesini AR, Nosari I, Trevisan R: Both continuous subcutaneous insulin infusion and a multiple daily insulin injection regimen with glargine as basal insulin are equally better than traditional multiple daily insulin injection treatment. Diabetes Care 2003;26:1321-1322.

33. Hirsch IB, Bode BW, Garg S, Lane WS, Sussman A, Hu P, Santiago OM, Kolaczynski JW: Continuous subcutaneous insulin infusion (CSII) of insulin aspart versus multiple daily injection of insulin aspart/insulin glargine in type 1 diabetic patients previously treated with CSII. Diabetes Care 2005;28:533-538.

34. Bode BW, Steed RD, Schleusener DS, Strange P: Switch to multiple daily injections with insulin glargine and insulin lispro from continuous subcutaneous insulin infusion with insulin lispro: a randomized, open-label study using a continuous glucose monitoring system. Endocr Pract 2005; 11:157-164.

35. Maran A, Crazzolara D, Nicoletti M, Costa S, dal Pos M, Tiengo A, Avogaro A, Bruttomesso D: A randomized crossover study to compare continuous subcutaneous insulin infusion (CSII) with multiple daily injection (MDI) in type 1 diabetic patients previously treated with CSII [abstract 902]. Diabetologia 2005;48:A328.

36. Bruttomesso D, Crazzolara D, Maran A, Costa S, Dal Pos M, Girelli A, Lepore G, Aragona M, Iori E, Valentini U, Del Prato S, Tiengo A, Buhr A, Trevisan R, Baritussio A: In Type 1 diabetic patients with good glycaemic control, blood glucose variability is lower during continuous subcutaneous insulin infusion than during multiple daily injections with insulin glargine. Diabet Med 2008;25:326-332.

37. Bolli GB, Kerr D, Thomas R, Torlone E, Sola-Gazagnes A, Vitacolonna E, Selam JL, Home PD: Comparison of a multiple daily insulin injection regimen (basal once-daily glargine plus mealtime lispro) and continuous subcutaneous insulin infusion (lispro) in type 1 diabetes: a randomized open parallel multicenter study. Diabetes Care 2009;32: 1170-1176.
38. Grimaldi A, Vialettes B, Blayo A, Brun JM, Halimi S: Comparison of dinner with bedtime administration of insulin glargine in type 1 diabetic patients treated with basal-bolus regimen. Diabetes Metab 2007;33:121-128.

39. Brown ML, Gersh BJ, Holmes DR, Bailey KR, Sundt TM $3^{\text {rd: }}$ From randomized trials to registry studies: translating data into clinical information. Nat Clin Pract Cardiovasc Med 2008;5:613-620.

40. Hannan EL: Randomized clinical trials and observational studies: guidelines for assessing respective strengths and limitations. JACC Cardiovasc Interv 2008;1:211-217.

41. Cramer JA, Pugh MJ: The influence of insulin use on glycemic control: how well do adults follow prescriptions for insulin? Diabetes Care 2005;28:78-83.

42. Lee WC, Balu S, Cobden D, Joshi AV, Pashos CL: Medication adherence and the associated health-economic impact among patients with type 2 diabetes mellitus converting to insulin pen therapy: an analysis of third-party managed care claims data. Clin Ther 2006;28:1712-1725; discussion 17101711.

43. Benson K, Hartz AJ: A comparison of observational studies and randomized, controlled trials. N Engl J Med 2000;342: 1878-1886.

44. Concato J, Shah N, Horwitz RI: Randomized, controlled trials, observational studies, and the hierarchy of research designs. N Engl J Med 2000;342:1887-1892.

45. Fischer JS, McLaughlin T, Loza L, Beauchamp R, Schwartz S, Kipnes M: The impact of insulin glargine on clinical and humanistic outcomes in patients uncontrolled on other insulin and oral agents: an office-based naturalistic study. Curr Med Res Opin 2004;20:1703-1710.

46. Albright ES, Desmond R, Bell DS: Efficacy of conversion from bedtime NPH insulin injection to once- or twice-daily injections of insulin glargine in type 1 diabetic patients using basal/bolus therapy. Diabetes Care 2004;27:632-633.

47. Conget I, Storms F, Rodriguez J, Leperlier C, Davies M, Gomis R: Changing from prior premix insulin regimen to insulin glargine in patients with type 1 diabetes: results from the AT.LANTUS trial [abstract 83]. Diabetologia 2004;47:A33.

48. Raz I, Storms F, Rodriguez J, Bianchi-Biscay M, Davies M, Gomis R: Changing from once- or twice-daily basal insulin to once-daily insulin glargine in adult type 1 diabetes: results from the AT.LANTUS trial [abstract 848]. Diabetologia 2004;47:A306.

49. Dabrowski M, Nowakowski A: [Long-term efficacy of insulin glargine in adult type 1 diabetic patients not controlled on previous treatment.] Diabetologia Doswiadczalna i Kliniczna 2007;7:178-183.

50. Schreiber SA, Russmann A: Long-term efficacy of insulin glargine therapy with an educational programme in type 1 diabetes patients in clinical practice. Curr Med Res Opin 2007;23:3131-3136.

51. Maia FF, Melo FJ, Araujo IM, Araujo LR: [Switching of NPH insulin to glargine therapy in a cohort of diabetic patients: observational study]. Arq Bras Endocrinol Metabol 2007;51:426-430.

52. Kanazawa Y, Igarashi Y, Komiya K, Sakurai Y, Shimizu T, Fujitani Y, Tanaka Y, Watada H, Kawamori R, Hirose T: Long-term efficacy of insulin glargine after switching from $\mathrm{NPH}$ insulin as intensive replacement of basal insulin in Japanese diabetes mellitus. Comparison of efficacy between type 1 and type 2 diabetes (JUN-LAN Study 1.2). Endocr J 2007;54:975-983. 
53. Currie CJ, Poole CD, Tetlow T, Holmes P, McEwan P: The outcome of care in people with type 1 and type 2 diabetes following switching to treatment with either insulin glargine or insulin detemir in routine general practice in the UK: a retrospective database analysis. Curr Med Res Opin 2007; 23(Suppl):S33-S39.

54. Daikeler R, Hogy B, Donaubauer B: [Effects of an intensified insulin therapy (ICT) with insulin glargine and insulin glulisine on patient reported outcomes (PRO) in diabetes mellitus.] Diabetologie und Stoffwechsel 2007;2:308-314.

55. Schreiber S, Ferlinz K, Donaubauer B: Efficacy of combining insulin glulisine with basal insulin glargine in patients with type I and type 2 diabetes previously on premix insulin therapy [abstract 0992]. Diabetologia 2007;50(Suppl 1): S410-S411.

56. Schreiber S, Landgraf W, Bohler S: [Efficacy and tolerability of insulin glargine in ICT.] Diabetes, Stoffwechsel und Herz 2009;8:91-98.

57. Sharplin P, Gordon J, Peters JR, Tetlow AP, Longman AJ, McEwan P: Switching from premixed insulin to glarginebased insulin regimen improves glycaemic control in patients with type 1 or type 2 diabetes: a retrospective primarycare-based analysis. Cardiovasc Diabetol 2009;8:9.

58. Sharplin P, Gordon J, Peters JR, Tetlow AP, Longman AJ, McEwan P: Improved glycaemic control by switching from insulin NPH to insulin glargine: a retrospective observational study. Cardiovasc Diabetol 2009;8:3.

59. Johansen OE, Vanberg PJ, Kilhovd BK, Jorgensen AP: Changing basal insulin from NPH to detemir or glargine in patients with type 1 diabetes and a history of severe hypoglycemia. Vasc Health Risk Manag 2009;5:121-128.

60. Ruhnau K: Introduction of insulin glulisine in combination with insulin glargine to basal-bolus therapy improves metabolic control in patients with type 1 diabetes in everyday clinical practice [abstract 2071-PO]. Diabetes 2006;55(Suppl 1):A479.

61. Winkler G, Martinka E, Genestin E, Paulbouter K: APIWATCH-interim results of a meta-analysis of pan-European real-life investigations with insulin glulisine to control A1c in type 1 diabetes [abstract 2006-PO]. Diabetes Care 2009;58:A514-A515.

62. Chase HP, Arslanian S, White NH, Tamborlane WV: Insulin glargine versus intermediate-acting insulin as the basal component of multiple daily injection regimens for adolescents with type 1 diabetes mellitus. J Pediatr 2008;153: 547-553.

63. Frohlich-Reiterer EE, Ong KK, Regan F, Salzano G, Acerini $\mathrm{CL}$, Dunger DB: A randomized cross-over trial to identify the optimal use of insulin glargine in prepubertal children using a three-times daily insulin regimen. Diabet Med 2007;24:1406-1411.

64. Murphy NP, Keane SM, Ong KK, Ford-Adams M, Edge JA, Acerini CL, Dunger DB: Randomized cross-over trial of insulin glargine plus lispro or $\mathrm{NPH}$ insulin plus regular human insulin in adolescents with type 1 diabetes on intensive insulin regimens. Diabetes Care 2003;26:799-804.
65. Schober E, Schoenle E, Van Dyk J, Wernicke-Panten K: Comparative trial between insulin glargine and NPH insulin in children and adolescents with type 1 diabetes. Diabetes Care 2001;24:2005-2006.

66. Schober E, Schoenle E, Van Dyk J, Wernicke-Panten K: Comparative trial between insulin glargine and NPH insulin in children and adolescents with type 1 diabetes mellitus. J Pediatr Endocrinol Metab 2002;15:369-376.

67. Hassan K, Rodriguez LM, Johnson SE, Tadlock S, Heptulla RA: A randomized, controlled trial comparing twice-a-day insulin glargine mixed with rapid-acting insulin analogs versus standard neutral protamine Hagedorn (NPH) therapy in newly diagnosed type 1 diabetes. Pediatrics 2008;121:e466-e472.

68. Mianowska B, Szadkowska A, Czerniawska E, Pietrzak I, Bodalski J: [Insulin glargine improves fasting blood glucose levels in prepubertal children with unsatisfactorily controlled type 1 diabetes]. Pediatr Endocrinol Diabetes Metab 2007;13:189-193.

69. Ashwell SG, Bradley C, Stephens JW, Witthaus E, Home PD: Treatment satisfaction and quality of life with insulin glargine plus insulin lispro compared with NPH insulin plus unmodified human insulin in individuals with type 1 diabetes. Diabetes Care 2008;31:1112-1117.

70. Witthaus E, Stewart J, Bradley C: Treatment satisfaction and psychological well-being with insulin glargine compared with NPH in patients with Type 1 diabetes. Diabet Med 2001;18:619-625.

71. Blonde L, Dey J, Testa MA, Guthrie RD: Defining and measuring quality of diabetes care. Prim Care 1999;26:841855.

72. Finkel ML: The importance of measuring patient satisfaction. Empl Benefits J 1997;22:12-15.

73. Biderman A, Noff E, Harris SB, Friedman N, Levy A: Treatment satisfaction of diabetic patients: what are the contributing factors? Fam Pract 2009;26:102-108.

74. Samann A, Muhlhauser I, Bender R, Kloos C, Muller UA: Glycaemic control and severe hypoglycaemia following training in flexible, intensive insulin therapy to enable dietary freedom in people with type 1 diabetes: a prospective implementation study. Diabetologia 2005;48:1965-1970.

75. Danne T: Flexibility of rapid-acting insulin analogues in children and adolescents with diabetes mellitus. Clin Ther 2007;29(Suppl D):S145-S152.

Address correspondence to: Satish Garg, M.D.

Barbara Davis Campus for Childhood Diabetes

University of Colorado Denver Anschutz Medical Campus Mail Stop A140

P.O. Box 6511

1775 Aurora Court

Aurora, CO 80045

E-mail: satish.garg@ucdenver.edu 